\title{
Rethinking NM23: An Extracellular role for NDPKinase in breast cancer
}

\author{
Iain L. O. Buxton* and Senny Nordmeier \\ Department of Pharmacology, University of Nevada School of Medicine, USA
}

\begin{abstract}
Ductal breast carcinoma, the most common breast cancer is not a rapidly developing disease. Many breast cancer deaths will be averted when we understand cellular mechanisms underlying spread and dormancy. We suggest that the description of $\mathrm{Nm} 23$ as a tumor suppressor is incomplete since the extracellular role of $\mathrm{Nm} 23$ in maintaining extracellular purines has received insufficient attention. Here we describe a basis for thinking differently about the role of Nm23 in breast cancer. Our study of the role of NME genes that encode nucleoside diphosphate kinase (Nm23/NDPKinase) is intended to contribute a basis for thinking differently about breast cancer spread and dormancy for the benefit of patients.
\end{abstract}

\section{Introduction}

Ductal breast carcinoma, the most common breast cancer is not a rapidly developing disease. Approximately 40,000 patients in the US die each year. Breast cancers can survive in a dormant state and grow as metastatic disease in the future even if detected at a relatively early state and managed surgically. Surgery to remove the primary tumor often accelerates relapse [1-5]. Many breast cancer deaths will be averted when we understand cellular mechanisms underlying spread and dormancy. We suggest that the description of $\mathrm{Nm} 23$ as a tumor suppressor [6] is incomplete since the extracellular role of $\mathrm{Nm} 23$ in maintaining extracellular purines has received insufficient attention. Since endothelial purinergic receptor stimulation activates VEGF receptor in the absence of VEGF, a mechanistic link between extracellular Nm23, a nucleoside diphosphate kinase (NDPKinase) and angiogenesis is known. Here we describe a basis for thinking differently about the role of $\mathrm{Nm} 23$ in breast cancer.

\section{A new approach}

Our approach, focused on the signaling exception represented by the appearance of NDPKinase outside breast cancer cells, brings innovation to the study of breast cancer. We propose a unifying hypothesis to encompass the observation that NDPKinase is elaborated by triple-negative breast tumor cells [7]. Recent evidence from our lab $[8]$ and others $[9,10]$ that NDPKinase is an exosomal signal suggests that the tumor suppressor and tumor promoter actions of NDPK are compartmented and that signaling evoked by exosomal NDPKinase (eNDPKinase) is mediated by extracellular purine nucleotides (Figure 1). The angiogenic response to P2YR/VEGF receptor signaling we have described with in vitro experimentation [11] suggests that a combination strategy targeting eNDPKinase could offer a therapeutic choice. Our study of the role of NME genes that encode nucleoside diphosphate kinase (Nm23/NDPKinase) is intended to contribute a basis for thinking differently about breast cancer spread and dormancy for the benefit of patients.

\section{NDPKinase}

NME1 and 2 (aka. NDPK-A and -B) function as NDPKinases regenerating ATP levels by covalently transferring the $\gamma$-phosphate from a nucleoside triphosphate (NTP) such as GTP, to a nucleoside diphosphate acceptor (NDP; e.g., ADP) effectively maintaing nucleotide levels in the vicinity of the kinase. This is the only known function of circulating NDPKinase [12], however, intracellular NDPKinase isozymes have been shown to act as a histidine kinase [13], a transcription activator and an exonuclease [14]. NDPKinase has been discovered in the exosomes of triple negative breast cancer cells and not the poorly metastatic MCF 7 cell [10]. Using directed proteomics, we found that triple-negative MDA-MB-231 Luc ${ }^{+}$cells elaborate exosomes containing 227 unique proteins including eNDPKinase, while (nontumorigenic) MCF-12F cells that elaborate exosomes containing 48 proteins, do not contain eNDPKinase [8].

There are ten isoforms of this plurifunctional protein [15,16], only two of which (NDPK-A and -B) are known to appear extracellularly [11]. NDPKinase is distributed in cytosol, mitochondria, plasma membrane and the nucleus [17]. Nm23 was originally described as nonmetastatic 23 gene found in mouse carcinoma cells as a homolog of the drosophila awd protein. Gene expression was thought to be inversely related to metastasis potential [6], although not exclusively [18-20]. Less attention was paid to the enzymatic function of NDPKinase in cancer and metastasis.

\section{Extracellular vesicles and exosomes}

It is known that cells release extracellular vesicles (EV) containing proteins as well as RNA species (and some even DNA), and that the size, origin and content of these vesicles vary and is disparate between normal and transformed cells [22]. We have shown that NDPKinase

Correspondence to: Iain L. O. Buxton, Foundation Professor and Chair, Pharmacology, Department of Pharmacology, University of Nevada School of Medicine, 1664 N. Virginia Street Reno, NV 89557-0318, USA, E-mail: ibuxton@medicine.nevada.edu

Key words: breast cancer, Nm23, NDPKinase, exosomes, metastasis

Received: May 09, 2015; Accepted: June 01, 2015; Published: June 03, 2015 
The Role of Nm23/eNDPKinase and Purine Nucleotides in Breast Cancer

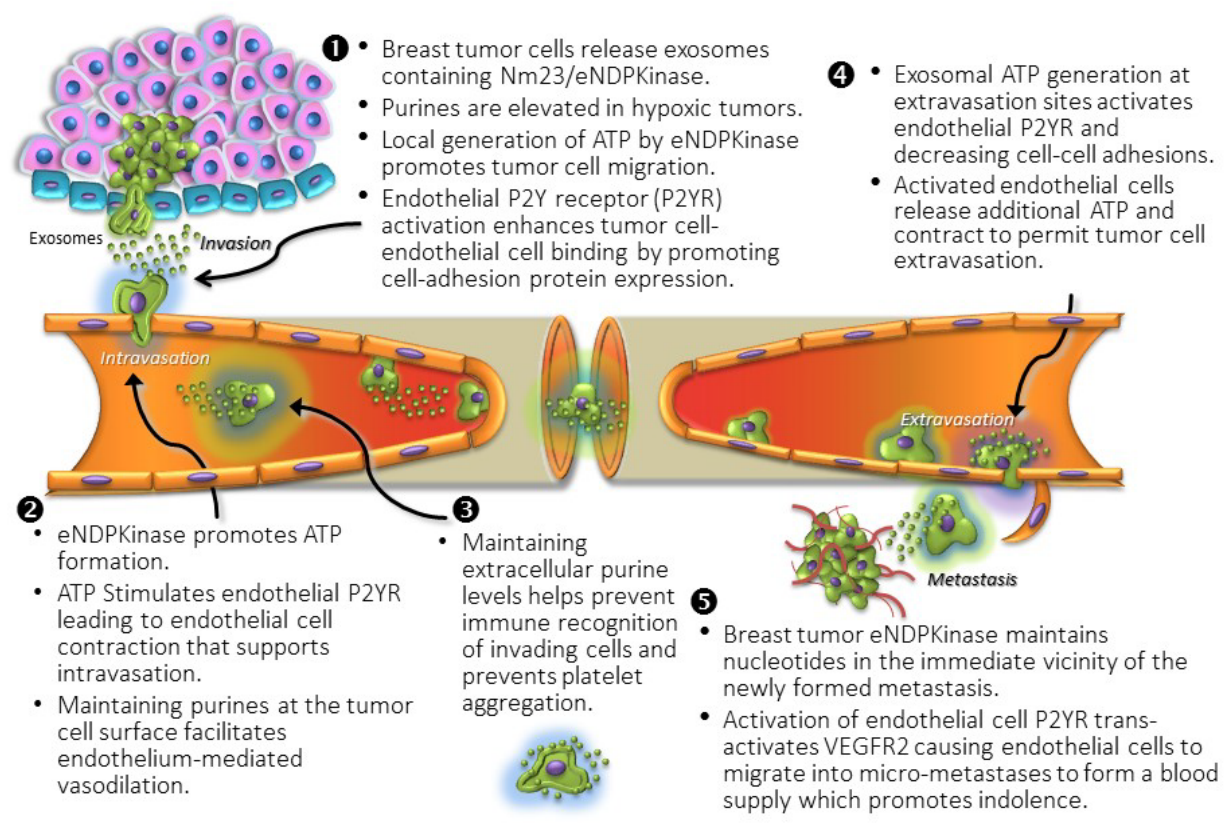

Figure 1. The role of Nm23/eNDP kinase and purine nucleotides in breast cancer

appears outside human ductal carcinoma cells [21] and is angiogenic. Resistance to acceptance of these ideas has been two fold; we could not explain how NDPKinase got out of cells to appear in the blood stream. Moreover, Nm23 was believed to be a tumor suppressor gene [23], while our data suggested otherwise [12].

The recent focus on EVs $[22,24]$ offers a context for understanding how NDPKinase can be released from cancer cells to act extracellularly. These smallest of the EVs were described in 1981 by Trams, et al. [25]. It is now possible to examine in detail the content of EVs [26]. Exosomes may represent a signaling vector for metastasis $[10,22]$, or even a delivery vehicle for cancer therapy [27]. There is much yet to learn about the nature and function of EVs. Excellent reviews are available $[28,29]$. We know that exosomes are elaborated by MDAMB-231 Luc ${ }^{+}$cells and that they express numerous proteins including eNDPKinase [8].

\section{NDPKinase and angiogenesis}

There is now evidence to support a role for $\mathrm{Nm} 23$ in promoting angiogenesis [7,30]. Addition of conditioned media from breast cancer cell lines known to contain NDPKinase transforms human endothelial cells in culture from monolayers to tubular structures and this is replicated by purified NDPKinase and blocked by inhibitors of NDPKinase. NDPKinase is diagnostic for kidney cancer [31] and associated with pancreatic cancer [32] and irritable bowel [33]. By focusing only on correlations between $\mathrm{Nm} 23$ gene expression; cellular inactivation, or expression of the mutant enzyme intracellularly with cancer outcomes, we miss the role of exosomal eNDPKinase in predicting the likelihood of progression to indolent disease. Our work showing secretion of eNDPKinase by breast cancer cells as well as its angiogenic action [34] and the molecular basis of its trans-activation of VEGFR2 [11] has set the stage for understanding its importance as an exosomal signal in angiogenesis leading to tumorigenesis and suggest that NDPKinase may be a survival factor in the metastatic niche.

\section{Not just a tumor suppressor}

The original description of $\mathrm{Nm} 23-\mathrm{H} 1$ as a tumor suppressor has received considerable attention [35], but exceptions to this notion have appeared for some time from our lab and others [7,11,34,36-43]. While seemingly contradictory, we suggest that the extracellular actions of $\mathrm{Nm} 23$ are distinct from those of overall cellular expression and the intracellular signaling that has been the focus of others [44]. The fact of NDPKinase appearing outside cells is established in vitro and in vivo $[45,46]$. Published evidence confirms that breast tumor cells release exosomal NDPKinase [8-10]. Amounts of eNDPKinase appearing extracellularly vary from one breast cancer cell type to another, but elaboration is a feature of breast cancer cells, not normal cells [11]. Two isoforms of NDPKinase, -A and -B (products of Nm23-H1 and -2) are elaborated by breast cancer cells [11]. When MBA-MB-231Luc cells are maintained in defined conditions in vitro with low serum (Gibco RPMI 1640 0.5\% FBS), cells elaborate more eNDPKinase when hypoxic and when stimulated with serum growth factors free of NDPKinase activity (Buxton, unpublished observation). These in vitro studies and those measuring ATP:P2YR - mediated growth stimulation, migration, tubule-like formations and signal transduction [34] have led us to suggest that NDPKinase is elaborated by breast tumor cells as eNDPKinase in exosomes in women with breast cancer and that this may be one of the mechanisms by which tumor cells move in the blood stream and attract a blood supply in vivo.

\section{Metastatic breast cancer is a latent disease}

In the developed world, by the time a woman has developed breast cancer she is most likely to have had some form of treatment including surgery. We have described the observation that excision of a primary 
tumor can cause tumor metastases to appear shortly thereafter [2-5] as an inconvenient truth [41]. We think it is intellectually displeasing to imagine that cells are "dislodged" during surgery and so think it reasonable to take this as evidence of subclinical distant metastases extant and indolent at the time of loco-regional treatment. This means that changes in cancer cells from quiescent to active growth occurred at some time following surgery. Demicheli et al. examined recurrence of breast cancer in 1173 pre-menopausal women suffering from aggressive breast cancer, who had a mastectomy but no other treatment. These patients showed an early peak in recurrence, with the majority around 18 months post-mastectomy [47]. Thus, recurrence is not only timedependent. This modal behavior indicates that surgery is somehow an aggravating event for some women and that there is an as yet ill-defined biological process underlying recurrence, with the result becoming clinically apparent approximately 18 months thereafter. There was a second mode of reoccurrence at 60 months; each correlated with larger (18 month peak) or smaller (60 month) primary tumors [4]. Dormancy (latency) prior to surgical removal may be a function of the primary tumor preventing the switch to angiogenesis and tumor growth being made [48].

These data argue that tumor cells present at distant sites at the time of surgery have existed in an indolent state ever since migrating from the site of the primary tumor early in tumor development. Such a conclusion is further supported by the knowledge that early detection of breast cancer does not prevent the later appearance of metastatic disease $[49,50]$. Indolent cells proliferate only once the anti-angiogenic effects of the primary tumor are removed, and/or have accumulated genetic changes required for emergence from quiescence [47,51]. Learning how cells enter and exit blood vessels and how they are able to maintain themselves in a dormant state prior to progression to metastatic disease offers a rationale for improving breast cancer treatment.

\section{Intravasation, extravasation and metastasis}

Normal cells move into and out of tissue spaces in the processes involved in development and immunity [52]. Tumor cells mimic many of these processes in their passage from primary tumor to metastatic site. The transendothelial migration of white blood cells out of the blood stream and into tissue spaces requires that they move between capillary cells and through basement membrane. This diapedesis or transendothelial migration, is known to involve the interaction of leukocytes with the vessel wall [53]. Intercellular adhesion molecule-1 and vascular cell adhesion molecule cluster on the endothelial cell and appear to be responsible for leukocyte binding based on interaction with specific leukocyte molecules (e.g., CD11, CD18, CD49 and CD29). The steps that follow involve both leukocyte and endothelial cell deformation to permit transit to occur [54].

It is known that locally generated ATP enhances leukocyte binding to endothelium [55] and that the expression of adhesion molecules by endothelium is enhanced by extracellular ATP acting at purine nucleotide receptors [56]. Moreover, polymorphonuclear leukocytes are known to elaborate ATP extracellularly themselves [57], so that along with endothelial cells that are well-known to elaborate ATP extracellularly [58], ATP receptors will be activated and endothelial permeability enhanced [59,60]. Rapid metabolism of ATP locally would generate adenosine consistent with reversing the permeability of the endothelium [61] and dilating venous vessels to facilitate flow down-stream [62].

\section{Vascular P2Y receptors-implications in metastasis}

Purinergic receptors [63] (P2YR) are recognized as regulators of carcinogenesis and endothelial cell functions and are modulators of platelet aggregation and blood flow regulation [64,65]. Extracellular ATP and ADP activate endothelial cell P2Y1 receptors to release vasoactive mediators such as nitric oxide, prostacyclin, and additional ATP $[58,64]$ to elicit vasoactive, proliferative and angiogenic effects [66]. Human endothelial $\mathrm{P}_{2} \mathrm{Y}_{1}$ receptors transactivate endothelial VEGFR-2, suggesting a direct link between extracellular nucleotide generation and growth factor signaling $[11,67]$ that fits with our hypothesis since in the absence of VEGF, inhibition of NDPKinase will prevent VEGFR-2 activation. A role for eNDPKinase in the process of metastasis is supported by disruption of CD39 (ecto-apyrase; EC3.6.1.5), the dominant vascular ecto-nucleotidase which has been observed to inhibit tumor angiogenesis and metastasis $[68,69]$. This would lead to decreased ADP levels in capillary vessels and decreased P2YR activation. We propose that eNDPKinase makes the metastatic niche receptive by endothelial activation and predicts the likelihood of progression to indolent disease by supporting dissemination and angiogenesis [11].

\section{Future concepts}

Our presentation of eNDPKinase as an exosomal factor by breast cancers in the pathogenesis of breast cancer metastasis offers a testable mechanistic hypothesis that challenges the notion that $\mathrm{Nm} 23$ is simply a tumor suppressor inversely correlated with metastasis potential. Our proposal expands the role of Nm23/NDPKinase by addressing its role as an exosomal kinase. Our hypothesis offers a concept of breast cancer biology that may apply broadly to solid tumor metastasis. Research on eNDPKinase may translate to new therapeutic targets in the treatment of human breast cancer. Such research will justify examining the polyphenols as eNDPKinase inhibitors and screening for more potent and specific eNDPKinase inhibitors and testing compounds that are P2YR antagonists to determine the likelihood that exosomal eNDPKinase can predict progression to metastatic disease and that non-toxic eNDPKinase and P2YR blockers can be developed as putative adjuvant supplements for treatment of women before surgery.

An intriguing aspect of our hypothesis is the possibility that breast cancer cell elaboration of eNDPKinase containing exosomes may prime the metastatic niche. It may be possible to test whether infusion of exosomes can make poorly metastatic cells survive and trigger more aggressive growth or that mutating the eNDPKinase to inactive kinase in exosomes might prevent or delay metastasis formation. It is possible that the exosome content arrives at the metastatic site in women before tumor cells arrive and that this paves the way for cells to survive in the niche with limited blood supply when they arrive and survive until additional events transform cells further leading to VEGF secretion and rapid growth consistent with escape from dormancy.

The ability of NDPKinase to phosphorylate three defined substrates, the $\beta$ subunit of heterotrimeric $G$ proteins $(G \beta)$, the intermediate conductance potassium channel $\mathrm{KCa} 3.1$, and the $\mathrm{Ca}^{2+}$-conducting TRP channel, TRPV5 [70,71], expand the possible importance of the kinase. These findings also suggest that engineering exosomes to deliver antiangiogenic therapies might be a treatment strategy in women early on in the course of their disease. It is possible that an individualized therapy involving growing cells from a woman's primary tumor that are engineered to produce exosomes containing anti-angiogenic or other anti-tumor treatment would be a form of individualized therapy worth developing. 


\section{References}

1. Schmidt-Kittler O, Ragg T, Daskalakis A, Granzow M, Ahr A, et al. (2003) From latent disseminated cells to overt metastasis: genetic analysis of systemic breast cancer progression. Proceedings of the National Academy of Sciences of the United States of America 100: 7737-7742.

2. Retsky M, Demicheli R, Hrushesky W, Baum M, Gukas I (2010) Surgery triggers outgrowth of latent distant disease in breast cancer: an inconvenient truth? Cancers (Basel) 2: 305-337. [Crossref]

3. Demicheli R, Biganzoli E, Boracchi P, Greco M, Retsky MW (2008) Recurrence dynamics does not depend on the recurrence site. Breast Cancer Res 10: R83. [Crossref]

4. Retsky MW, Demicheli R, Hrushesky WJ, Baum M, Gukas ID (2008) Dormancy and surgery-driven escape from dormancy help explain some clinical features of breast cancer. APMIS 116: 730-741. [Crossref]

5. Retsky M, Demicheli R, Hrushesky WJ (2005) Does surgery induce angiogenesis in breast cancer? Indirect evidence from relapse pattern and mammography paradox. Int J Surg 3: 179-187. [Crossref]

6. Steeg PS, Bevilacqua G, Pozzatti R, Liotta LA, Sobel ME (1988) Altered expression of NM23, a gene associated with low tumor metastatic potential, during adenovirus 2 Ela inhibition of experimental metastasis. Cancer Res 48: 6550-6554. [Crossref]

7. Rumjahn SM, Javed MA, Wong N, Law WE, Buxton IL (2007) Purinergic regulation of angiogenesis by human breast carcinoma-secreted nucleoside diphosphate kinase. $\mathrm{Br} \mathrm{J}$ Cancer 97: 1372-1380. [Crossref]

8. Wong S, Speirs K, Duan S, Buxton ILO (2015) MDA-MB-231 Cell Exosomes Contain Nucleoside Diphosphate Kinase. Reproductive Science (T-041): $121 \mathrm{a}$.

9. Palazzolo G, Albanese NN, DI Cara G, Gygax D, Vittorelli ML, et al. (2012) Proteomic analysis of exosome-like vesicles derived from breast cancer cells. Anticancer Res 32 : 847-860. [Crossref]

10. Kruger S, Abd Elmageed ZY, Hawke DH, Wörner PM, Jansen DA, et al. (2014) Molecular characterization of exosome-like vesicles from breast cancer cells. BMC Cancer 14: 44. [Crossref]

11. Yokdang N, Tellez JD, Tian H, Norvell J, Barsky SH, et al. (2011) A role for nucleotides in support of breast cancer angiogenesis: heterologous receptor signalling. Br J Cancer 104: 1628-1640. [Crossref]

12. Buxton IL, Yokdang N, Matz RM (2010) Purinergic mechanisms in breast cancer support intravasation, extravasation and angiogenesis. Cancer Lett 291: 131-141. [Crossref]

13. Attwood PV, Wieland T (2015) Nucleoside diphosphate kinase as protein histidine kinase. Naunyn Schmiedebergs Arch Pharmacol 388: 153-160. [Crossref]

14. Postel EH (2003) Multiple biochemical activities of NM23/NDP kinase in gene regulation. J Bioenerg Biomembr 35: 31-40. [Crossref]

15. Lacombe ML, Milon L, Munier A, Mehus JG, Lambeth DO (2000) The human Nm23 nucleoside diphosphate kinases. J Bioenerg Biomembr 32: 247-258. [Crossref]

16. McDermott WG, Boissan M, Lacombe ML, Steeg PS, Horak CE (2008) Nm23-H1 homologs suppress tumor cell motility and anchorage independent growth. Clin Exp Metastasis 25: 131-138. [Crossref]

17. Bertheau P, De La Rosa A, Steeg PS, Merino MJ (1994) NM23 protein in neoplastic and nonneoplastic thyroid tissues. Am J Pathol 145: 26-32. [Crossref]

18. Hailat N, Keim DR, Melhem RF, Zhu XX, Eckerskorn C, et al. (1991) High levels of p19/nm23 protein in neuroblastoma are associated with advanced stage disease and with $\mathrm{N}$-myc gene amplification. J Clin Invest 88: 341-345. [Crossref]

19. Melhem RF, Zhu XX, Hailat N, Strahler JR, Hanash SM (1991) Characterization of the gene for a proliferation-related phosphoprotein (oncoprotein 18) expressed in high amounts in acute leukemia. J Biol Chem 266: 17747-17753. [Crossref]

20. Keim D, Hailat N, Melhem R, Zhu XX, Lascu I, et al. (1992) Proliferation-related expression of $\mathrm{p} 19 / \mathrm{nm} 23$ nucleoside diphosphate kinase. J Clin Invest 89: 919-924. [Crossref]

21. Buxton IL, Yokdang N, Matz RM (2010) Purinergic mechanisms in breast cancer support intravasation, extravasation and angiogenesis. Cancer Lett 291: 131-141. [Crossref]

22. Vader P, Breakefield XO, Wood MJ (2014) Extracellular vesicles: emerging targets for cancer therapy. Trends Mol Med 20: 385-393. [Crossref]

23. Steeg PS, Bevilacqua G, Sobel ME, Liotta LA(1991) Identification and characterization of differentially expressed genes in tumor metastasis: the nm23 gene. Basic Life Sci 57: 355-360. [Crossref]

24. Rak J (2013) Extracellular vesicles - biomarkers and effectors of the cellular interactome in cancer. Front Pharmacol 4: 21. [Crossref]

25. Trams EG, Lauter CJ, Salem N Jr, Heine U (1981) Exfoliation of membrane ectoenzymes in the form of micro-vesicles. Biochim Biophys Acta 645: 63-70. [Crossref]

26. Jenjaroenpun P, Kremenska Y, Nair VM, Kremenskoy M, Joseph B, et al. (2013) Characterization of RNA in exosomes secreted by human breast cancer cell lines using next-generation sequencing. Peer $J$ 1: e201. [Crossref]

27. Vader P, Kooijmans SA, Stremersch S, Raemdonck K (2014) New considerations in the preparation of nucleic acid-loaded extracellular vesicles. Ther Deliv 5: 105-107. [Crossref]

28. Yuana Y, Sturk A, Nieuwland R (2013) Extracellular vesicles in physiological and pathological conditions. Blood Rev 27: 31-39. [Crossref]

29. Natasha G, Gundogan B, Tan A, Farhatnia Y, Wu W, et al. (2014) Exosomes as immunotheranostic nanoparticles. Clin Ther 36: 820-829. [Crossref]

30. Rumjahn SM, Yokdang N, Baldwin KA, Thai J, Buxton IL (2009) Purinergic regulation of vascular endothelial growth factor signaling in angiogenesis. Br J Cancer 100: 1465 1470. [Crossref]

31. Su Kim D, Choi YD, Moon M, Kang S, Lim JB, et al. (2013) Composite three-marker assay for early detection of kidney cancer. Cancer Epidemiol Biomarkers Prev 22: 390398. [Crossref]

32. Takadate T, et al. (2012) Nm23/nucleoside diphosphate kinase-A as a potent prognostic marker in invasive pancreatic ductal carcinoma identified by proteomic analysis of laser micro-dissected formalin-fixed paraffin-embedded tissue. Clinical proteomics 9 : 8. [Crossref]

33. Ohya S, Fukuyo Y, Kito H, Shibaoka R, Matsui M, et al. (2014) Upregulation of $\mathrm{KCa} 3.1 \mathrm{~K}(+)$ channel in mesenteric lymph node $\mathrm{CD} 4(+) \mathrm{T}$ lymphocytes from a mouse model of dextran sodium sulfate-induced inflammatory bowel disease. Am J Physiol Gastrointest Liver Physiol 306: G873-885. [Crossref]

34. Rumjahn SM, Yokdang N, Baldwin KA, Thai J, Buxton IL (2009) Purinergic regulation of vascular endothelial growth factor signaling in angiogenesis. Br J Cancer 100: 1465 1470. [Crossref]

35. Marino N, Nakayama J, Collins JW, Steeg PS (2012) Insights into the biology and prevention of tumor metastasis provided by the $\mathrm{Nm} 23$ metastasis suppressor gene. Cancer Metastasis Rev 31: 593-603. [Crossref]

36. Okabe-Kado J, Kasukabe T, Honma Y, Hanada R, Nakagawara A, et al. (2005) Clinical significance of serum NM23-H1 protein in neuroblastoma. Cancer Sci 96: 653-660. [Crossref]

37. Niitsu N, Nakamine H, Okamoto M, Akamatsu H, Higashihara M, et al. (2004) Clinical significance of intracytoplasmic nm23-H1 expression in diffuse large B-cell lymphoma. Clin Cancer Res 10: 2482-2490. [Crossref]

38. Niitsu N, Nakamine H, Okamoto M, Akamatsu H, Honma Y, et al. (2003) Expression of nm23-H1 is associated with poor prognosis in peripheral T-cell lymphoma. $\mathrm{Br} J$ Haematol 123: 621-630. [Crossref]

39. Niitsu N, Okamoto M, Honma Y, Nakamine H, Tamaru JI, et al. (2003) Serum levels of the nm23-H1 protein and their clinical implication in extranodal NK/T-cell lymphoma. Leukemia 17: 987-990. [Crossref]

40. Okabe-Kado J, Kasukabe T (2003) Physiological and pathological relevance of extracellular NM23/NDP kinases. J Bioenerg Biomembr 35: 89-93. [Crossref]

41. Buxton IL, Yokdang N (2011) Extracellular NM23 Signaling in Breast Cancer Incommodus Verum. Cancers (Basel) 3: 2844-2857. [Crossref]

42. Yokdang N, Buxton ND, Buxton IL (2009) Measurement of human breast tumor cellsecreted shNDPK-B in a murine breast cancer model suggests its role in metastatic progression. Proc West Pharmacol Soc 52: 88-91. [Crossref]

43. Buxton IL (2008) Inhibition of $\mathrm{Nm} 23 \mathrm{H} 2$ gene product (NDPK-B) by angiostatin, polyphenols and nucleoside analogs. Proc West Pharmacol Soc 51: 30-34. [Crossref]

44. Iiizumi M, Liu W, Pai SK, Furuta E, Watabe K (2008) Drug development against metastasis-related genes and their pathways: a rationale for cancer therapy. Biochim Biophys Acta 1786: 87-104. [Crossref]

45. Anzinger J, Malmquist NA, Gould J, Buxton IL (2001) Secretion of a nucleoside diphosphate kinase $(\mathrm{Nm} 23-\mathrm{H} 2)$ by cells from human breast, colon, pancreas and lung tumors. Proc West Pharmacol Soc 44: 61-63. [Crossref] 
46. Yokdang N, Buxton IL (2010) A Role for hNDPK-B in Breast Cancer Metastasis in vivo. In: Proceedings of the 101st Annual Meeting, American Association of Cancer Research Tumor Biology (LB-366): 467.

47. Demicheli R, Retsky MW, Hrushesky WJ, Baum M (2007) Tumor dormancy and surgery-driven interruption of dormancy in breast cancer: learning from failures. $\mathrm{Nat}$ Clin Pract Oncol 4: 699-710. [Crossref]

48. Alix-Panabières C, Müller V, Pantel K (2007) Current status in human breast cancer micrometastasis. Curr Opin Oncol 19: 558-563. [Crossref]

49. Amar S1, McCullough AE, Tan W, Geiger XJ, Boughey JC, et al. (2010) Prognosis and outcome of small $(<=1 \mathrm{~cm})$, node-negative breast cancer on the basis of hormonal and HER-2 status. Oncologist 15: 1043-1049. [Crossref]

50. Tryfonidis K, Zardavas D, Cardoso F (2014) Small breast cancers: when and how to treat. Cancer Treat Rev 40: 1129-1136. [Crossref]

51. Schardt JA, Meyer M, Hartmann CH, Schubert F, Schmidt-Kittler O, et al. (2005) Genomic analysis of single cytokeratin-positive cells from bone marrow reveals early mutational events in breast cancer. Cancer Cell 8: 227-239. [Crossref]

52. Christofori G (2006) New signals from the invasive front. Nature 441: 444-450. [Crossref]

53. Muller WA (2003) Leukocyte-endothelial-cell interactions in leukocyte transmigration and the inflammatory response. Trends Immunol 24: 327-334. [Crossref]

54. Rowe RG, Weiss SJ (2008) Breaching the basement membrane: who, when and how? Trends Cell Biol 18: 560-574. [Crossref]

55. Sud'ina GF, Mirzoeva OK, Galkina SI, Pushkareva MA, Ullrich V (1998) Involvement of ecto-ATPase and extracellular ATP in polymorphonuclear granulocyte-endothelial interactions. FEBS Lett 423: 243-248. [Crossref]

56. Ferrero ME (2009) A new approach to the inflammatory/autoimmune diseases. Recent Pat Antiinfect Drug Discov 4: 108-113. [Crossref]

57. Eltzschig HK, Eckle T, Mager A, Küper N, Karcher C, et al. (2006) ATP release from activated neutrophils occurs via connexin 43 and modulates adenosine-dependent endothelial cell function. Circ Res 99: 1100-1108. [Crossref]

58. Yang S, Cheek DJ, Westfall DP, Buxton IL (1994) Purinergic axis in cardiac blood vessels. Agonist-mediated release of ATP from cardiac endothelial cells. Circ Res 74: 401-407. [Crossref]
59. Tanaka N, Kawasaki K, Nejime N, Kubota Y, Nakamura K, et al. (2004) P2Y receptormediated $\mathrm{Ca}(2+)$ signaling increases human vascular endothelial cell permeability. $J$ Pharmacol Sci 95: 174-180. [Crossref]

60. Tanaka N, Nejime N, Kagota S, Kubota Y, Yudo K, et al. (2006) ATP participates in the regulation of microvessel permeability. J Pharm Pharmacol 58: 481-487. [Crossref]

61. Eltzschig HK, Weissmüller T, Mager A, Eckle T (2006) Nucleotide metabolism and cell-cell interactions. Methods Mol Biol 341: 73-87. [Crossref]

62. Berne RM (1980) The role of adenosine in the regulation of coronary blood flow. Circ Res 47: 807-813. [Crossref]

63. White N, Burnstock G (2006) P2 receptors and cancer. Trends Pharmacol Sci 27: 211217. [Crossref]

64. Buxton IL, Kaiser RA, Oxhorn BC, Cheek DJ (2001) Evidence supporting the Nucleotide Axis Hypothesis: ATP release and metabolism by coronary endothelium. Am J Physiol Heart Circ Physiol 281: H1657-1666. [Crossref]

65. Burnstock G (2006) Pathophysiology and therapeutic potential of purinergic signaling. Pharmacol Rev 58: 58-86. [Crossref]

66. Kashiwagi S, Izumi Y, Gohongi T, Demou ZN, Xu L, et al. (2005) NO mediates mura cell recruitment and vessel morphogenesis in murine melanomas and tissue-engineered blood vessels. J Clin Invest 115: 1816-1827. [Crossref]

67. Seye CI, Yu N, Gonzalez FA, Erb L, Weisman GA (2004) The P2Y2 nucleotide receptor mediates vascular cell adhesion molecule-1 expression through interaction with VEGF receptor-2 (KDR/Flk-1). J Biol Chem 279: 35679-35686. [Crossref]

68. Goepfert C, Sundberg C, Sévigny J, Enjyoji K, Hoshi T, et al. (2001) Disordered cellular migration and angiogenesis in cd39-null mice. Circulation 104: 3109-3115. [Crossref]

69. Jackson SW, Hoshi T, Wu Y, Sun X, Enjyoji K, et al. (2007) Disordered purinergic signaling inhibits pathological angiogenesis in cd39/Entpd1-null mice. Am J Pathol 171: 1395-1404. [Crossref]

70. Burnstock G (2006) Purinergic signalling. Br J Pharmacol 147: S172-181. [Crossref]

71. Attwood PV, Wieland T (2015) Nucleoside diphosphate kinase as protein histidine kinase. Naunyn Schmiedebergs Arch Pharmacol 388: 153-160. [Crossref]

Copyright: $\odot 2015$ Buxton ILO. This is an open-access article distributed under the terms of the Creative Commons Attribution License, which permits unrestricted use, distribution, and reproduction in any medium, provided the original author and source are credited. 